\title{
Platelet production by megakaryocytes: protoplatelet theory justifies cytoplasmic fragmentation model
}

\author{
Goro Kosaki
}

Published online: 4 June 2009

(C) The Japanese Society of Hematology 2009

Erratum to: Int J Hematol (2008) 88:255-267

DOI 10.1007/s12185-008-0147-7

There are errors in the online version of this article. Correct version is provided as Electronic Supplementary Material, which is available to authorized users.

The online version of the original article can be found under doi:10.1007/s12185-008-0147-7.

Electronic supplementary material The online version of this article (doi:10.1007/s12185-009-0339-9) contains supplementary material, which is available to authorized users.

G. Kosaki

Surgery II, Osaka University Medical School, Osaka, Japan

G. Kosaki ( $\square)$

2-5-51-2 Toneyama, Toyonaka, Osaka 560-0045, Japan

e-mail: sakon@nishi.or.jp 